\title{
Spinal intramedullary cysticercosis: a case report and literature review
}

\author{
Audrey Beatriz Santos Araujo', Marina Brugnoli Ribeiro Cambraia², Ricardo Azevedo \\ Moraes Motta Filho², Gláucia Lara Rezende ${ }^{3}$, Alander Sobreira Vanderlei
}

Department of Neurosurgery, Hospital Odilon Behrens, Belo Horizonte, MG, Brazil.

\begin{abstract}
Neurocysticercosis is an endemic infeccion in Brazil, but the intramedullary cases are rare, $1,2 \%$ to $5,8 \%$ of all cases. There are only fifty cases reported until January of 2011. Intramedullary neurocysticerosis is a treatable pathology but if misdiagnosed it could lead to irreversible damage. Twenty eight year old female patient, previously healthy, was admitted due to a fall. She had progressive walking difficulties and impaired sensation in both lower limbs two months before admission. Contrast MRI revealed a round intramedullary cystic lesion at T2 e T3. The patient underwent laminectomy from $T 2$ to $T 3$, and the spinal cord was found locally swollen near the exit root at this level. A mielotomy was performed where a round protrusion was seen near the root. Histological examination of the resected sample showed cysticercosis. After surgical excision she received albendazol and streoids. The patient's neurological function postoperatively was unchanged. One week later, the motor power of her lower limbs were grade $4 / 5$, and she could walk without special support. The function of anal sphincter and bladder regained without compromise. She was back to work. This reflects dramatically in an active portion of population since it affects mostly people between 20 to 45 years. So it still represents a challenge and this paper intend to show our experience and by that help future diagnostics.
\end{abstract}

\section{KEYWORDS}

Neurocysticercosis, spinal cord, cysticercosis/terapy.

\section{RESUMO}

Cisticercose intramedular: relato de caso e revisão da literatura

A neurocisticercose é uma doença endêmica no Brasil, mas os casos de lesão intramedular são raros, representando $1,2 \%$ a 5,8\% das neurocisticercoses. Há apenas 50 casos relatados até 2011 na literatura. É uma patologia potencialmente tratável, mas erro diagnóstico pode causar dano neurológico irreversível. Apresentamos um caso de paciente de 28 anos, previamente hígida, admitida após uma queda. Relatava fraqueza progressiva e déficit sensitivo em membros inferiores com dois meses de evolução. Ressonância magnética revelou lesão cística intramedular em T2-T3. A paciente foi submetida à laminectomia T2-T3, com mietomia e ressecção de lesão cística completa. Exame histológico revelou cisticercose. Realizaremos revisão da literatura com ênfase no diagnóstico e tratamento da neurocisticercose medular, que podem representar um desafio ao neurocirurgião.

\section{PALAVRAS-CHAVE}

Neurocisticercose, medula espinal, cisticercose/terapia.

1 MD, Neurosurgeon, Medical Assistant, Department of Neurosurgery, Hospital Odilon Behrens, Belo Horizonte, MG, Brazil.

2 MD, Medical Resident, Department of Neurosurgery, Hospital Odilon Behrens, Belo Horizonte, MG, Brazil.

3 MD, Neurologist, Medical Assistant, Department of Neurosurgery, Hospital Odilon Behrens, Belo Horizonte, MG, Brazil. 


\section{Introduction}

Neurocysticercosis is caused by the larval stage of the pork tapeworm Taenia solium. ${ }^{1}$ In 1913, Ferguson apud Qi et al. ${ }^{2}$ was the first to describe a case of spinal cysticercosis. Cysticercosis is the most common parasitic infection affecting the central nervous system. However, the spinal cysticercosis is rare, representing $0.7 \%$ to $5.8 \%$ of all cases of neurocysticercosis.

This disease has been classified anatomically as extraspinal (vertebral) or intraspinal (epidural, subdural, arachnoid, or intramedullary), of which the intramedullary type is quite rare. In fact, only 55 cases have been reported up to January of 2011..$^{2-4}$

The present study aims to report a case of intramedullary cysticercosis at T2 and T3 vertebral levels and discuss its diagnosis and treatment through a literature review.

\section{Clinical presentation}

\section{History}

A previously healthy 28-year-old female patient was admitted to the Odilon Behrens hospital after a fall equal to the patient's height. The patient reported progressive walking difficulties and impaired sensations in both lower limbs, but worse in the right lower limb. She also reported having suffered of incomplete bladder evacuation for three weeks, but no anal sphincter dysfunction could be identified. She claimed that she was feeling no pain. The symptoms, however, had begun, approximately, two months before admission. She had already searched for medical help at another institution one month prior, when a computed tomography (CT) of the lumbar spine had been performed. The CT proved to be normal and the doctor's advice was physical therapy. However no improvement could be observed.

\section{Examination}

Neurological examination revealed spastic paraparesis with a decreased motor power of grade $3 / 5$ in both lower limbs and impaired sensations below the T6 dermatome. Clonus, brisk tendon jerks and signs of positive Babinski could be identified on both sides of the body.

\section{Complementary exams}

Contrast MRI revealed a round intramedullary cystic lesion at T2 and T3 vertebral levels, which were homogeneously hypointense with hyperintense ring on T1WI and hyperintense on T2WI with a hyperintense signal on the adjacent level. The subarachnoid space from $\mathrm{T} 2$ to $\mathrm{T} 3 \mathrm{w}$ ws narrow due to the marked expansion of the spinal cord (Figure 1A-C). No abnormalities could be observed at the cervical level or within the brain parenchyma.
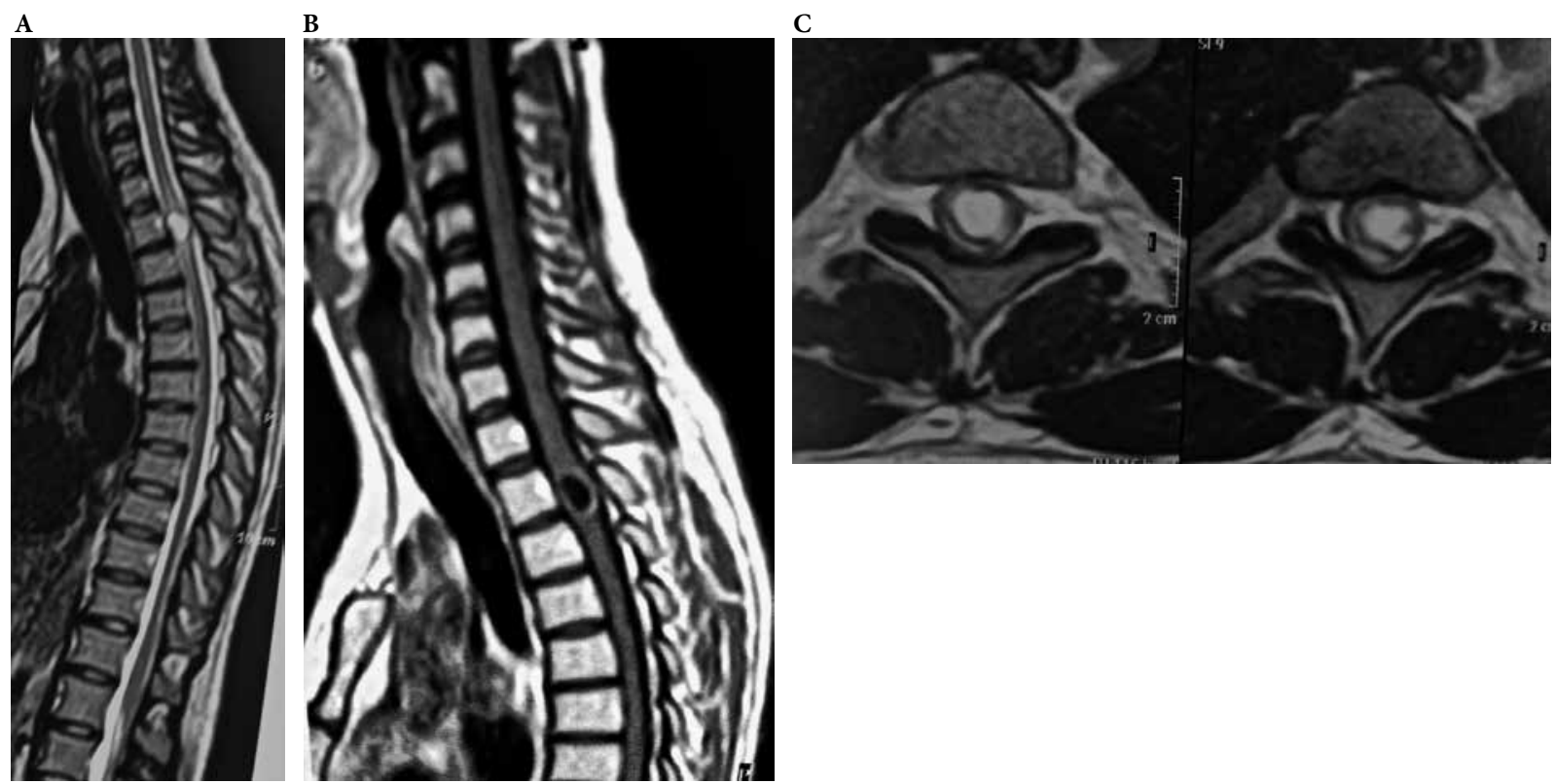

Figure 1 - (A) Sagital T2WI MR image of the cervicothoracic region demonstrating round intramedullary cystic lesion at T2 and T3 vertebral levels, hyperintense on T2WI with a hyperintense signal on the adjacent levels. The subarachnoid space from T2 to T3 was narrow due to the marked expansion of the spinal cord. (B) Sagital T1WI MR image demonstrating the same cystic lesion, hypointense with a hyperintense ring. (C) Axial non - contrast T2WI image of T2/T3 level. 


\section{Other findings}

She was submitted to pulse therapy with methylprednisolone for 5 days, followed by prednisone therapy before surgery while awaiting an MRI. After the first five days of steroid treatment the patient showed improvement of her neurological functions. The lower limbs progressed to motor power grade $4 / 5$.

\section{Operation}

The patient underwent laminectomy from $\mathrm{T} 2$ to $\mathrm{T} 3$, and the spinal cord was found to be locally swollen near the exit root at this level. A mielotomy was performed where a round protrusion was seen near the root exit. A white cystic lesion protruding from the incision site could immediately be seen (Figures 2 and 3A, B). The cyst wall presented a good cleavage to the surrounding spinal cord. No cystic liquid was withdrawn and the cyst was fully removed (Figure 3A, B).

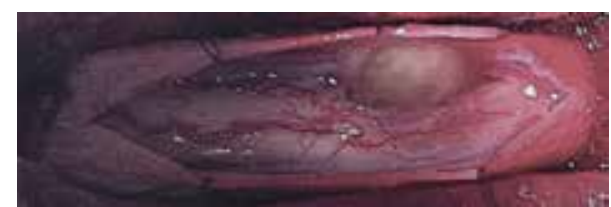

Figure 2 - Image of the cystic lesion protunding from the mielotomy point at T2/T3 with a good cleavage to the surrounding spinal cord after laminectomy and opening of the dura.

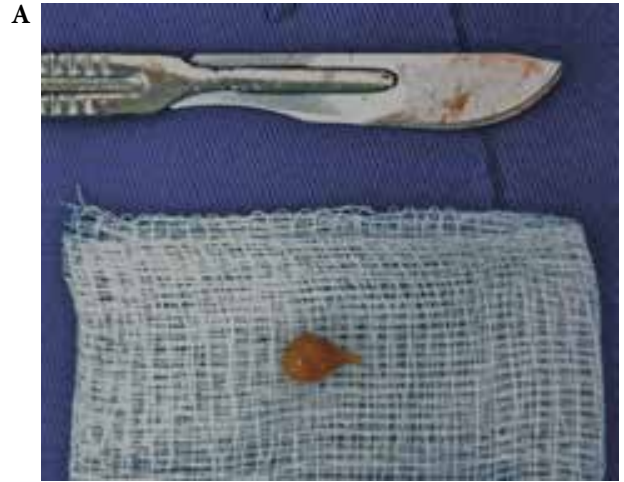

B

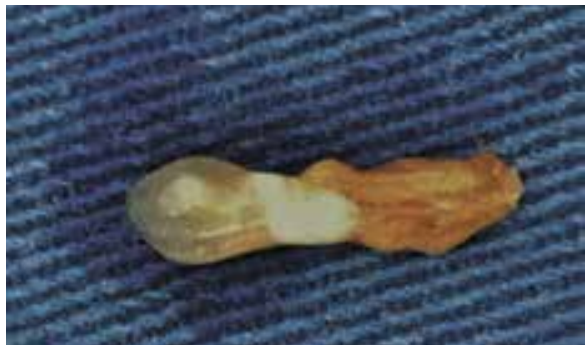

Figure 3 - (A) Nodular cystic lesion with brown granular tissue surrounding it. (B) After excision of the granular tissue, it was possible to see the cyst in its vesicular stage and the larva inside with a marginal projecting nodule (scolex) surrounded by clear cyst fluid within a thin capsule.

\section{Patological findings}

Histological examination of the ressected sample showed cysticercosis (Figure 4).

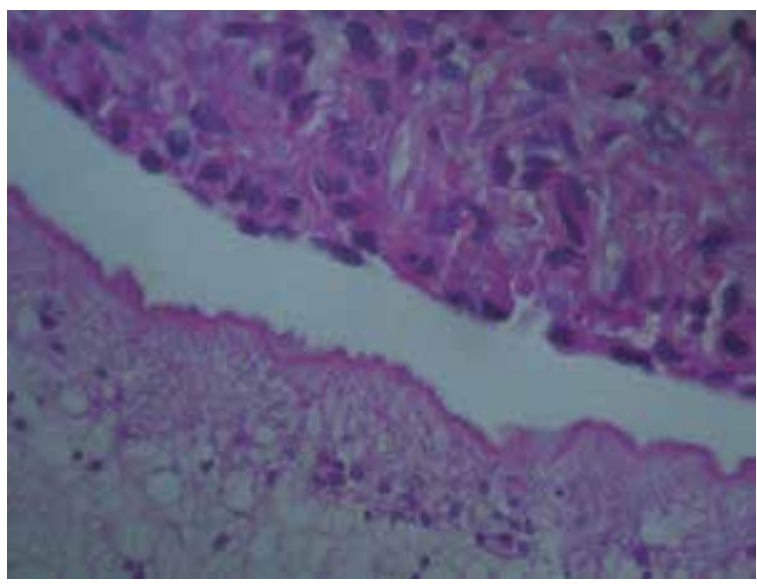

Figure 4-Histological appearance of the resected cyst.

\section{Postoperative course}

The patient was treated with albendazol $400 \mathrm{mg}$, twice a day, for three days and steroids (dexamethasone $4 \mathrm{mg}$ IV 6/6h). The patient's postoperative neurological function remained was unchanged and she was discharged from the hospital three days later. One week later, the motor power of her lower limbs reached grade $4 / 5$, and she could walk without special support. She also regained the functioning of her anal sphincter and bladder without sequelas and has now returned to work.

\section{Discussion and review of literature}

Cysticercosis is widely endemic in Brazil. ${ }^{5}$ Intramedullary cysticercosis often appears in patients between 20 to 45 years of age but it is considered rare even in endemic areas, with an incidence ranging between $0.7 \%$ and $5.8 \% .^{2}$

Four forms of spinal neurocysticercosis have been identified: vertebral, extradural, intradural extramedullary and intramedullary, the most common being intradural extramedullary. Intramedullary cysticercosis is quite rare with about half of the reported cases presenting concomitant extra spinal involvement. ${ }^{6}$

Extramedullary form occurs due to a CSF dissemination (ventricle ependymal migration) of the focus in the brain, whereas intramedullary forms result 
due to a hematogeneous spread of the parasitic larvae. Intramedullary cysticercosis is the most common in the thoracic spine due to high vascularity of this spinal segment. ${ }^{7}$ For the same reason brain cysticercosis is more common than spinal cysticercosis.

Most patients with the disease experienced a progressively worsened course of symptoms from the first week to 10 years. ${ }^{7}$ The common clinical manifestations include pain, paraparesis, spasticity, bowel and bladder incontinence, and sexual dysfunction. ${ }^{3,7}$

Neurological manifestations can be produced by the parasite itself causing mechanical compression and obstruction, surrounding inflammation, cord edema and residual scarring as well as pachymeningitis or syrinx formation. ${ }^{6}$ Inflammatory reaction against the dead parasite is associated with perilesional edema, which can damage medullar parenchyma and therefore, worsen symptoms. ${ }^{6}$

The role of MRI in the diagnosis of neurocysticercosis is well documented. This exam aids not only in the diagnosis, but also in the preoperative localization of the lesion and the extent of involvement. In an MRI, intramedullary cysticercosis commonly appears as a cystic lesion within the spinal cord, which is hypointense on T1WI with hyperintense escolex identified inside the cyst cavity and hyperintense on T2WI in the vesicular stage. A subtle hypointense rim may surround the intramedullary cyst on T2WI. In the colloidal stage, the thickened cyst capsule is hyperintense on T1WI and hypointense on the T2WI. Cyst contents appear hyperintense on T1WI and that result in scolex that could not be observed. The disease commonly presents a significant amount of surrounding edema. If cyst degeneration is present, peripheral ring enhancement may also be present. . $^{3,4,6,8}$

The differential diagnosis of an intramedullary cystic lesion is extensive, including some other cysts such as arachnoid cyst, ${ }^{9}$ ependymal cyst, ${ }^{10}$ neurenteric cyst ${ }^{11}$ among other pathologies: sarcoidosis, ${ }^{12}$ neoplasms such as ependymoma; infections such as abscesses, ${ }^{13}$ posttraumatic syrinx and metastases.

The CSF examination often shows increased proteins, a low or normal glucose level, moderate lymphocytic pleocytosis and eosinophilia. ${ }^{14}$ Cysticercal antibodies found in CSF either by ELISA or in serum by enzyme-linked immunoelectric transfer bolt assay have presented good sensitivity and specificity in cysticercosis diagnosis. ${ }^{14,15}$

The pathological finding depends upon the stage of the cyst. In the vesicular stage, the larva is approximately $5 \mathrm{~mm}$ diameter, with a marginal projecting nodule (scolex) surrounded by clear cyst fluid within a thin capsule (live cyst). The colloidal vesicular stage suggests the initial stages of degeneration and mineralization. The cyst fluid becomes turbid and jelly like and the capsule thickens. In the granular nodular phase, cyst retraction occurs due to mineralized and granular contents. Capsule thickness collagenises and hyalinises in degenerating aging cysts. Adjacent neural tissue shows inflammatory changes in the form of increased vascularity, capillary endothelial proliferation, infiltration by lymphocytes, plasma cells, eosinophils, histiocytes and multinucleated giant cells, along with edema and gliosis. These, however, are absent in live cysts. Finally, these changes reduce and vanish once the cyst has been totally mineralized as a calcific nodule. ${ }^{4}$

Mohanty et al. ${ }^{16}$ reported only a $75 \%$ satisfactory outcome after surgery and cysticidal treatment. Sharma et al. ${ }^{7}$ reported that $60 \%$ acquired improvement after surgery, $25 \%$ did not improve and $15 \%$ died. In the reports published in recent years, surgical outcome significantly improved with no cases of death and the majority of patients where able to live a life without the need for special support. ${ }^{3,4,6,17,18}$ Surgery is a procedure of choice only when the diagnosis is doubtful; otherwise medical treatment is preferred. ${ }^{3}$

Albendazole is a medicine that has been proven to be effective in the patients with intramedullary cysticercosis since $1996 .{ }^{19}$ Preoperative adjunctive treatment with albendazole is thought to be helpful to consolidate the lesion and thus induce a clear plane of dissection during surgery. Albendazole is normally used postoperatively as a regular treatment ( $15 \mathrm{mg} / \mathrm{kg} /$ day) for 4 to 6 weeks, according to the idea that cysticercosis is a generalized disease with focal manifestation. Moreover, albendazole is often used with corticosteroids, given that it's blood level could be synergistically increased by the latter. ${ }^{20}$ Albendazole can also be used independently in the conservative treatments for patients suspected of being infected with intramedullary cysticercosis and when clinical courses prove to be stable. However, this treatment may not be possible in an acute or progressive neurological state. The potential advantages of medical therapy alone include avoiding surgery and treatment of surgically unreachable and multifocal cysticercus. ${ }^{1,6,8,14,19,21,22}$

Postoperative anticysticercal drugs should be instituted, as cysticercosis is a generalized disease with a focal manifestation. ${ }^{1}$

\section{Conclusion}

This patient recovered all of her motor function and was able to return to her normal activities. But this outcome can only be expected when the correct treatment of this disease has been implemented. 
Hence, neurocysticercosis should always be considered in differential diagnoses. Both surgery and clinical treatment are important for the treatment of this pathology. It can therefore be concluded that intramedullary cysticercosis represents a treatable pathology that if misdiagnosed can lead to a delay in treatment and an increase in morbidity. This finding can be seen in a large portion of the active population. Neurocysticercosis still represents a medical challenge; therefore, this work intends to show the present research group's experience in an attempt to aid future diagnoses of this disease.

\section{Competing interests}

There are no conflicts of interests, no financial disclosure and it is approved by an Ethical Comittee.

\section{References}

1. Azfar SF, Kirmani S, Badar F, Ahmad I. Isolated intramedullary spinal cysticercosis in a 10-year-old female showing dramatic response with albendazole. J Pediatr Neurosci. 2011;6(1):52-4.

2. Qi B, Ge P, Yang H, Bi C, Li Y. Spinal intramedullary cysticercosis: a case report and literature review. Int J Med Sci. 2011;8(5):420-3.

3. Agrawal R, Chauhan SP, Misra V, Singh PA, Gopal NN. Focal spinal intramedullary cysticercosis. Acta Biomed. 2008;79(1):39-41.

4. Mathuriya SN, Khosla VK, Vasishta RK, Tewari MK, Pathak A, Prabhakar S. Intramedullary cysticercosis: MRI diagnosis. Neurol India. 2001;49(1):71-4.

5. Takayanagui OM, Leite JP. Neurocysticercosis. Rev Soc Bras Med Trop. 2001;34(3):283-90.

6. Ahmad FU, Sharma BS. Treatment of intramedullary spinal cysticercosis: report of 2 cases and review of literature. Surg Neurol. 2007;67(1):74-7.

7. Sharma BS, Banerjee AK, Kak VK. Intramedullary spinal cysticercosis. Case report and review of literature. Clin Neurol Neurosurg. 1987;89(2):111-6.

8. Parmar H, Shah J, Patwardhan V, Patankar T, Patkar $D$, Muzumdar $D$, et al. MR imaging in intramedullary cysticercosis. Neuroradiology. 2001;43(11):961-7.
9. Lmejjati M, Aniba K, Haddi M, Hakkou M, Ghannane H, Ait Ben Ali S. Spinal intramedullary arachnoid cyst in children. Pediatr Neurosurg. 2008;44(3):243-6.

10. Iwahashi H, Kawai S, Watabe Y, Chitoku S, Akita N, Fuji T, et al. Spinal intramedullary ependymal cyst: a case report. Surg Neurol. 1999;52(4):357-61.

11. Pianetti Filho G, Fonseca LF. High medular compression caused by neurenteric cyst. Report of a case. Arq Neuropsiquiatr. 1993;51(2):253-7.

12. Clifton AG, Stevens JM, Kapoor R, Rudge P. Spinal cord sarcoidosis with intramedullary cyst formation. $\mathrm{Br} \mathrm{J}$ Radiol. 1990;63(754):805-8.

13. Tacconi L, Arulampalam T, Johnston FG, Thomas DG. Intramedullary spinal cord abscess: case report. Neurosurgery. 1995;37(4):817-9.

14. Garg RK, Nag D. Intramedullary spinal cysticercosis: response to albendazole: case reports and review of literature. Spinal Cord. 1998;36(1):67-70.

15. Tsang VC, Brand JA, Boyer AE. An enzyme-linked immunoelectrotransfer blot assay and glycoprotein antigens for diagnosing human cysticercosis (Taenia solium). $\mathrm{J}$ Infect Dis. 1989;159(1):50-9.

16. Mohanty A, Venkatrama SK, Das S, Das BS, Rao BR, Vasudev MK. Spinal intramedullary cysticercosis. Neurosurgery. 1997;40(1):82-7.

17. Homans J, Khoo L, Chen T, Commins DL, Ahmed J, Kovacs A. Spinal intramedullary cysticercosis in a five-year-old child: case report and review of the literature. Pediatr Infect Dis J. 2001;20(9):904-8.

18. Corral I, Quereda C, Moreno A, López-Vélez R, MartínezSan-Millán J, Guerrero A, et al. Intramedullary cysticercosis cured with drug treatment. A case report. Spine (Phila Pa 1976). 1996;21(19):2284-7.

19. Jung H, Hurtado M, Medina MT, Sanchez M, Sotelo J. Dexamethasone increases plasma levels of albendazole. J Neurol. 1990;237(5):279-80.

20. Chhiber SS, Singh B, Bansal P, Pandita KK, Razdan S, Singh $\mathrm{J}$. Intramedullary spinal cysticercosis cured with medical therapy: case report and review of literature. Surg Neurol. 2009;72(6):765-8

21. Savage JJ, Casey JN, McNeill IT, Sherman JH. Neurenteric cysts of the spine. J Craniovertebr Junction Spine. 2010;1(1):58-63.

22. De Sousa AA, Dantas FL, Vega MG, Pereira WF, Souza C. Cisticercose intramedular. Arq Neuropsiquiatr. 1999;57(2):301-5.

Correspondence address

Audrey Beatriz Santos Araujo

Av. Bernardo Vasconcelos, 2600/304, Ipiranga

31160-440 - Belo Horizonte, MG, Brasil

Telefone: (055 31) 3344-4838

E-mail: franciscoaudrey@uol.com.br 